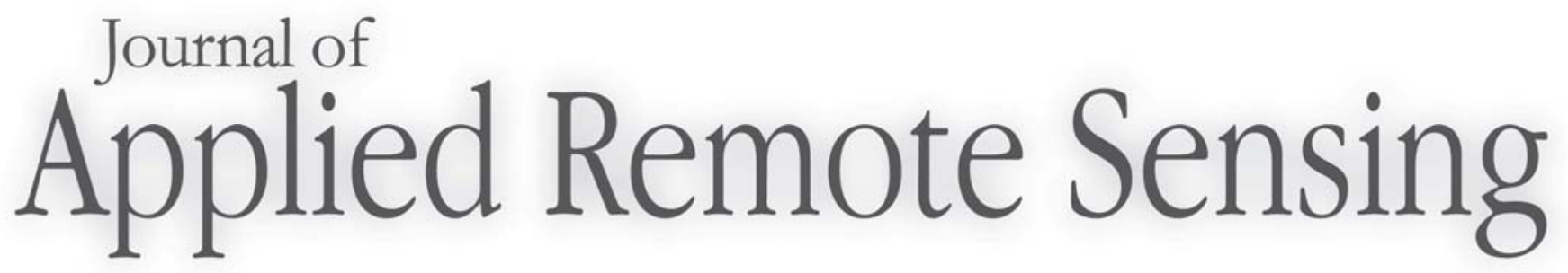

\title{
Guest Editorial: Remote Sensing for Coupled Natural Systems and Built Environments
}

Ni-Bin Chang 


\title{
Guest Editorial: Remote Sensing for Coupled Natural Systems and Built Environments
}

\author{
Ni-Bin Chang \\ University of Central Florida, Department of Civil, Environmental, and Construction \\ Engineering, 4000 Central Florida Boulevard, Orlando, FL 32816 \\ nchang@mail.ucf.edu
}

This special section on remote sensing for coupled natural systems and built environments is composed of full-length papers selected from different areas of expertise that enhance the fundamental understanding of the complex interactions within and among natural and human systems. The aim of this special section is to present significant contributions from several research groups working on different approaches and to find solutions to one of the greatest challenges of our era, that is, the global change in an environmental context. This aim may include but is not limited to climate change, rapid urbanization, natural hazard, food scarcity, biodiversity, economic development and globalization, and population growth and migration. To deal with these emerging issues, the papers in this special section emphasize an integrated, quantitative, systems-level method of remote sensing that is essential for tracking down the dynamics of coupled natural and human systems. To fulfill this goal, the guest editor gathered scientists from the USA, Iran, Japan, China, South Africa, Taiwan, Finland, Germany, and other countries to discuss outstanding research on a multitude of topics and disciplines that are highly interdisciplinary and focus on systems. Such an effort provides readers with an exceptional opportunity to learn about how remote sensing technologies can promote deepened insights of the complex interactions among human and natural systems at diverse spatial, temporal, and organizational scales. Each of these publications highlights some specific contributions that are well grounded in relevant remote sensing theory from a range of appropriate fields and demonstrate the contemporary state-of-the-art accomplishments and future trends in remote sensing for environmental management. All of them collectively lead future researchers to explore new methods and techniques for more environmental applications. Finally, it is indeed a great pleasure for me to see so many eminent scholars from different countries sharing their valuable experience with this ever-growing community. I wish to thank every author and reviewer for his or her enthusiastic contributions to this special section. 